\title{
Análise da decisão do Recurso Especial no 982.923-PR: aspectos essenciais do direito fundamental à saúde e ao meio ambiente equilibrado em caso de contaminação de lençol freático
}

Analysis of the decision of Recurso Especial no 982.923-PR: essential aspects of the fundamental right to health and the balanced environment in case of groundwater contamination

Análisis de la decisión del Recurso Especial no 982.923-PR: aspectos esenciales del derecho fundamental a la salud y al medio ambiente equilibrado en caso de contaminación de napas freáticas

Danielle Antpack Bettim ${ }^{1}$

Rafael Ferreira Costa ${ }^{2}$

\section{Introdução}

Este trabalho trata de aspectos essenciais relativos ao julgamento do Recurso Especial no 982.923-PR (1). Por oportuno, colaciona-se a ementa do julgado:

Ação coletiva. Associação de moradores. Produtos tóxicos. Contaminação. Água. Danos morais e materiais. Direitos individuais homogêneos. Caracterização.

1 - A quantificação dos danos morais e materiais fica relegada à liquidação de sentença e, por isso mesmo, não impede a subsunção da espécie à definição legal de direitos individuais homogêneos, caracterizados por um fato comum, no caso específico o vazamento de produtos tóxicos e a contaminação da água consumida pelos associados.

2 - Recurso especial conhecido e provido para reconhecer a legitimidade ativa ad causam da recorrente.

(REsp 982.923/PR, Rel. Ministro FERNANDO GONÇALVES, QUARTA TURMA, julgado em 10/06/2008, DJe 12/08/2008)

Nesse sentido, na decisão, enquanto se discute a legitimidade ativa ad causam, o caso de fundo - objeto de análise deste artigo - trata de condenação à indenização de danos morais e materiais, bem como da obrigação de fazer (isto é, proceder à descontaminação e à recuperação de áreas degradadas) a que foi condenada a ora recorrida (empresa poluente) em virtude de ter promovido o armazenamento de tambores de resíduos tóxicos inadequadamente (os quais continham "borra de tinta" reciclada). Essa negligência acarretou a poluição do meio ambiente e, sobretudo, a contaminação das águas que abasteciam os

\footnotetext{
${ }_{1}^{1}$ Mestranda pelo Programa de Pós-Graduação da Universidade Federal do Rio Grande do Sul (PPGDir/UFRGS), na área de concentração Direito Privado. Graduada em Ciências Jurídicas e Sociais. E-mail: danielleantpack@gmail.com

2 Advogado, mestrando em Direito Econômico (PPGDir/UFRGS), pós-graduado em Direito Tributário (IBET), pósgraduando em Direito Público (ESMAFE). E-mail: rfcosta.edu@gmail.com
} 
bairros em que moravam os membros da associação (cerca de 800 pessoas); por consequência, houve o adoecimento de diversos moradores do Jardim Cristal e Jardim Marambaia.

A propósito, a importância desse julgado é ilustrada na sua seleção para incluir o rol de jurisprudência relevante constante no Informativo no 359/2008, do Superior Tribunal de Justiça. A par disso, a pertinência temática transdisciplinar ao direito sanitário ocorre a partir das graves consequências à saúde de toda uma comunidade, decorrentes da poluição ao meio ambiente (contaminação da água) e das medidas judiciais levadas a cabo para a solução dessa questão.

Assim, uma vez escolhida à decisão paradigma, para se efetuar a sua análise doutrinária, este breve artigo será estruturado da seguinte forma: primeiramente, será tratado o regime de regulamentação das águas e de formas de sua contaminação. Na parte dois, será abordada a resposta legal a esse dano causado, isto é, o tratamento jurídico concedido à matéria no que tange aos direitos fundamentais à saúde e ao meio ambiente equilibrado.

Nessa senda, aqui ainda será abordada não só a questão dos direitos individuais homogêneos, como também o tema dos resíduos sólidos mal armazenados - o que, no caso concreto, levou à contaminação das águas, causando o adoecimento dos moradores locais. Esclarece-se, por oportuno, que a responsabilidade por dano ambiental envolve as dimensões penal, cível e administrativa, sem abrir mão da dimensão sanitária.

À guisa de introdução do tema, é importante salientar que a preocupação com a disponibilidade de água potável é um tema que ascendeu apenas nas últimas décadas como preocupação de fato. Em consequência disso, eram escassos os estudos sobre o tema, cuja regulamentação encontrava-se no Código de Águas (Decreto no 24.643/1934) (2). Além disso, encontrava-se presente no Código Civil de 2002 (3), nos artigos 1.288 a 1.296, de modo que a questão da água era tratada mormente como problema de vizinhança. (4)

Na década de 1980, por meio de ações civis públicas, o quadro passou a mudar: o Ministério Público passou a deter o necessário instrumento processual para promover a sua atuação nos casos de dano ambiental, sobretudo com a vigência da Lei no 7.347/1985 (5), que incrementou o instrumental de proteção ambiental à disposição do parquet. (4)

Nesse diapasão, várias ações, julgadas procedentes, se sucederam no sentido de promover a proteção ambiental; por exemplo, julgou-se procedente ação contra indústria 
que lançava poluentes em rio sem tratamento (TJSP, in RT 639/130), bem como outra demanda que objetivava o impedimento de atividade agrícola com uso de agrotóxico em área de preservação ambiental destinada à captação de água para o abastecimento da população. (4)

\section{1. Águas: formas de contaminação, sua classificação e seu regramento jurídico}

\subsection{Classificação e Contaminação das Águas}

Nesta parte do trabalho, será abordada a classificação das águas, bem como as suas formas de contaminação. Dessa forma, quanto à classificação das águas, pode-se distinguilas nas categorias legislativa e doutrinária.

Pela classificação legislativa, a partir do critério dos usos preponderantes (sistema de classes de qualidade) atuais e futuros ${ }^{3}$, as águas classificam-se em: doces, salobras e salinas. A Resolução do Conselho Nacional do Meio Ambiente (CONAMA) no 357/2005 (6), de 17 de março de 2005, preceitua o seguinte:

art. $2^{\circ}$ Para efeito desta Resolução são adotadas as seguintes definições:

I - águas doces: águas com salinidade igual ou inferior a 0,5\%;

II - águas salobras: águas com salinidade superior a 0,5\% e inferior a 30 $\%$;

III - águas salinas: águas com salinidade igual ou superior a $30 \%$; (...)

Pela classificação doutrinária, de acordo com Freitas (7), as águas classificam-se em: (a) subterrâneas e superficiais; (b) internas e externas; (c) doces e salgadas.

As águas subterrâneas são as armazenadas a certa profundidade do solo e subsolo, a exemplo dos lençóis freáticos. As águas superficiais são as que se mostram na superfície da Terra, como os rios e lagos.

As águas internas são as que banham exclusivamente o território nacional ou the servem de divisa com Estados estrangeiros. As águas externas são as que contornam o continente, compreendendo o mar territorial, as águas contíguas e o alto-mar.

Por fim, água doce é o corpo de água que contém resíduo mineral menor do que 0,1\%, com proporções variáveis de carbonato, bicarbonato e sulfatos. Água salgada é a solução complexa, de composição variável e geralmente de alta condutividade, determinada pelo

\footnotetext{
${ }^{3}$ Conforme inciso X, do art. $2^{\circ}$ da Resolução $357 / 2000$ do CONAMA.
} 
equilíbrio entre a taxa de adição e a perda de solução por evaporação de água doce, a exemplo dos mares.

No que tange à contaminação das águas, sobretudo as subterrâneas, está pode se dar de diversas formas. Em que pese às subterrâneas sejam mais protegidas do que rios e lagos (devido à maior exposição destes), elas têm sido afetadas a cada dia com maior intensidade. Nas palavras de Freitas, existem fatores que acarretam essa contaminação, os quais se elencam na sequência:

"os depósitos irregulares de lixo, usinas de açúcar, destilarias de álcool, curtumes, matadouros, frigoríficos, vazamentos em oleodutos, aterros, lixões, insumos agrícolas, fossas sépticas, negligência no encaminhamento de óleo dos postos de gasolina, cemitérios, etc". (4)

Ademais, importa frisar como ocorre o processo de penetração da água no solo, de modo a "formar" as reservas aquíferas subterrâneas. Conforme Gerent e Gonçalves (8)

a penetração da água no solo dá-se através de um processo natural e o caminho percorrido no subsolo e sua purificação são explicados por reações físico-químicas. A extração das águas subterrâneas ocorre em quase todos os países do mundo, servindo não apenas ao abastecimento doméstico, mas também ao industrial e à irrigação. Assim, as funções dos aquíferos são diversas, além de estocarem excedentes de água durante as enchentes dos rios e filtrarem a água.

Portanto, neste item abordou-se a classificação das águas e os modos pelos quais ela é contaminada. No tópico seguinte, será analisada a sua sistematização normativa.

\subsection{Regime jurídico dos recursos hídricos}

No que diz respeito ao regime jurídico que normatiza a questão das águas no Brasil, trata-se genericamente do tema no artigo 23, IV, da Constituição Federal de 1988 (9). Relativamente às águas subterrâneas, estas são tratadas no artigo 26, I, da Carta Magna, em que se consigna que elas são bens dos Estados. (10)

No plano infraconstitucional, tem-se vigente a Lei no. 9.433/1997 (11), que institui a Política Nacional de Recursos Hídricos e cria o Sistema Nacional de Gerenciamento de Recursos Hídricos, regulamentando o artigo 21, XIX, da Constituição Federal (9). O seu conteúdo normativo está direcionado para a regulamentação das águas superficiais, de modo que não faz menção expressa às águas subterrâneas. (4)

Ainda no plano da legislação federal, a Lei №. 9.984/2000 (12) dispõe sobre a criação da Agência Nacional de Águas (ANA), cuja função precípua é zelar pelos corpos de água de 
domínio da União. Nesse contexto, apesar da vigência das leis federais acima mencionadas, quando a legislação federal é omissa a legislação federal, a estadual irá dispor sobre a matéria. (4)

Além disso, cabe ressaltar a Lei Complementar nº. 140/2011 (13), a qual define, em síntese, normas para a cooperação relativamente ao exercício da competência comum na proteção do meio ambiente e no combate à poluição em qualquer de suas formas (artigo 23, VI, da Constituição Federal), especialmente em questões de licenciamento ambiental. Ademais, sublinham-se as Resoluções do CONAMA (Conselho Nacional do Meio Ambiente) no. 357/2005 (6), 370/2006 (14), 393/2007 (15) e 397/2008 (16), as quais complementam a legislação infraconstitucional, estabelecendo parâmetros administrativos e níveis toleráveis de poluição nas águas doces, salobras e salinas.

É digno de nota, por fim, que as águas minerais possuem legislação à parte. Sobre o tema, ressalta Freitas (4)

\begin{abstract}
Elas podem aflorar à superfície ou permanecer como jazida no interior da terra. Nesta segunda hipótese, o tratamento jurídico que recebem está previsto de forma específica no Decreto-lei no. 227/1967, conhecido como Código de Mineração. No art. 3ํㅗ desse diploma legal está estipulado que a pesquisa e exploração cabem ao departamento Nacional da Produção Mineral - DNPM e a autorização ao Ministério das Minas e Energia.
\end{abstract}

Desse modo, uma vez analisada a questão jurídica e doutrinária das águas, passa-se ao breve exame do direito fundamental à saúde e ao meio ambiente equilibrado, bem como sobre a política nacional sobre resíduos sólidos.

\title{
2. Direito Fundamental à Saúde e ao Meio Ambiente Equilibrado
}

O direito fundamental à saúde é expressamente previsto na Constituição Federal. Nesse sentido, cabe ressaltar os seguintes artigos 6º, 196, 197, 199 e, em especial, os incisos II, VI e VII, do artigo 200, além das normas de competência: (i) comum (art. 23, inciso II); (ii) legislativa concorrente (art. 24, inciso XII); (iii) suplementar dos Municípios (art. 30, inciso VII).

Em tempo, no art. 225, caput, da Constituição Federal, reconhece-se o direito fundamental ao meio ambiente ecologicamente equilibrado, elevando o grau de proteção jurídica que teve início com a Lei no․ 6.938/1981 (17). Segundo Steigleder (4), trata-se de um direito formal - pois é cláusula pétrea, integra a Constituição escrita e vincula as 


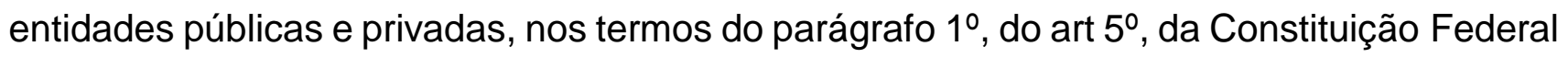
- e materialmente fundamental, porque compõe a Constituição material e contem decisões sobre a estrutura básica do Estado e da sociedade.

Analisados os direitos fundamentais à saúde e ao meio ambiente equilibrado, passase ao estudo da tutela coletiva do direito à saúde (tópico 2.1), assim como da política nacional dos resíduos sólidos e as consequências de seu mal armazenamento (tópico 2.2).

\title{
2.1 Tutela Coletiva do Direito à Saúde
}

Com relação à tutela coletiva do direito à saúde, dispõe o mencionado artigo 81, em seu inciso III do parágrafo único:

\begin{abstract}
art. 81. A defesa dos interesses e direitos dos consumidores e das vítimas poderá ser exercida em juízo individualmente, ou a título coletivo.

Parágrafo único. A defesa coletiva será exercida quando se tratar de: [...]

III - interesses ou direitos individuais homogêneos, assim entendidos os decorrentes de origem comum.
\end{abstract}

Consoante Nunes (18), os direitos individuais homogêneos são caracterizados por conterem: (i) sujeito ativo determinado e plural, o que permite o ingresso dos legitimados dispostos no art. 82, do CDC, sem impedir o manejo de ações individuais; (ii) como sujeito passivo, todos aqueles que direta ou indiretamente tenham causado o dano, ou ainda, participado ou contribuído para o evento danoso; (iii) na relação jurídica, um vínculo a partir de uma origem comum a todos os titulares do direito violado; (iv) um objeto divisível: o resultado concreto da violação é diverso a cada titular do direito individual homogêneo; (v) enquadramento como espécie de direito coletivo: os direitos individuais homogêneos são uma espécie de direito coletivo. Ou seja, o efeito da violação a um direito coletivo também gera um direito individual ou individual homogêneo.

Portanto, no caso em tela, verificamos que se trata claramente de violação de direitos individuais homogêneos, pois a negligência no armazenamento de produtos tóxicos, gerou o vazamento de produtos tóxicos no lençol freático (danos ambientais) e a contaminação da água consumida pelos associados (danos à saúde).

\subsection{Política Nacional dos Resíduos Sólidos e a hipótese de resíduos sólidos mal armazenados}

No que tange ao regime jurídico concernente aos resíduos sólidos, conforme Machado (19), a Lei nº 12.305/10 institui a Política Nacional de Resíduos Sólidos (PNRS) e está 
regulamentada pelo Decreto Federal n 7.404/10 (21). Foi elaborada com base no artigo 24, VI e VIII, da Constituição Federal. Por ser norma geral, utilizou-se da competência concorrente, não excluiu a competência suplementar dos Estados (art. 24, §º) nem dos Municípios (art. 30, I e II), no que couber. Assim, a União não tem competência privativa para legislar sobre resíduos sólidos.

Em suma, de acordo com Antunes (22), a PNRS visa à regulamentação da gestão integrada e do gerenciamento ambientalmente adequado de resíduos sólidos, incluídos os resíduos perigosos, assim como a responsabilidade dos geradores e do poder público, visando mitigar os danos oriundos da inadequada disposição final de resíduos sólidos.

Dentre uma série de princípios, objetivos, instrumentos, diretrizes e definições, a PNRS traz não só as diretrizes para os planos de resíduos sólidos (art. 14, da PNRS), mas também o dever de responsabilidade compartilhada, de logística reversa, dentre várias outras disposições. Outrossim, coloca maior responsabilidade aos fabricantes e importadores, atribuindo-lhes um dever duplo: um quanto à disposição dos produtos e embalagens e outro concernente aos rejeitos, de acordo com Machado (19).

Acerca da hipótese de mal armazenamento de resíduos sólidos, entabulada na decisão paradigma objeto de análise deste trabalho, segundo Machado (19), a responsabilidade civil é de natureza objetiva ou independentemente de culpa, nos mesmos termos do artigo 14, da Lei $n \cong$. 6.938/1998 (17), enquanto que a responsabilidade penal requer a culpa para a sua configuração.

Nessa senda, o artigo 54 da Lei no 9.605/1998 (23) prevê sanções penais relativamente aos resíduos sólidos, enquanto que o Decreto $\mathrm{n}^{\circ}$ 6.514, de 22 de julho de 2008 (24), administrativas, a exemplo do art. 61 com especial atenção aos incisos III e V do art. 62, que preveem multa de $\mathrm{R} \$ 5.000,00$ (cinco mil reais) a $\mathrm{R} \$ 50.000 .000,00$ (cinqüenta milhões de reais), para quem:

III - causar poluição hídrica que torne necessária a interrupção do abastecimento público de água de uma comunidade;

V - lançar resíduos sólidos, líquidos ou gasosos ou detritos, óleos ou substâncias oleosas em desacordo com as exigências estabelecidas em leis ou atos normativos;

No caso concreto, de um lado, embora ainda não estivesse vigente a PNRS, verificouse a negligência da empresa que violou todos os instrumentos legais para a manutenção e prevenção da poluição ambiental. De outro lado, com o advento da PNRS, a 
responsabilidade da empresa aumentaria significativamente, por meio, inclusive, da adoção de planos de resíduos sólidos, com possibilidade de sanções administrativas, cíveis e penais mais gravosas do que as aplicadas no acórdão paradigma.

Portanto, nesse tópico foram abordadas a política nacional dos resíduos sólidos e as consequências de seu mal armazenamento.

\section{Considerações Finais}

A partir do caso proposto, verificamos que a efetivação do direito fundamental à saúde está intrinsecamente ligada à concretização do direito fundamental ao meio ambiente ecologicamente equilibrado. O ordenamento jurídico brasileiro dispõe de um conjunto complexo de ações públicas e privadas, assim como de serviços públicos de saúde para atingir tais objetivos.

Nesse sentido, tornam-se imprescindíveis as medidas tanto sanitárias quanto ambientais de controle, monitoramento, fiscalização e responsabilização, não só para prevenir a poluição e a contaminação das águas, como também, para a realização de medidas de recuperação de áreas degradadas em caso de poluição acima dos limites permitidos.

Portanto, podemos inferir que, além da responsabilidade socioambiental das empresas e do Poder Público, realçada com o advento da Lei no 12.305/2010 (Política Nacional dos Resíduos Sólidos) (25), o Estado dispõe de mecanismos administrativos e jurídicos aptos à prevenção de danos ambientais, ao monitoramento e à responsabilização jurídica dos causadores de danos à saúde e ao meio ambiente.

\section{Referência}

1- $\quad$ Superior Tribunal de Justiça. Recurso Especial ํo 982.923-PR (2007/0216331-8). Recorrente: Associação dos Moradores do Jardim Cristal e Jardim Marambaia. Recorrido: Saint - Gobain Abrasivos Brasil Ltda. Relator: Ministro Fernando Gonçalves. Paraná, 10 jun 2008. T4, 4ํㅡㄹ Turma. Disponível em:

https://stj.jusbrasil.com.br/jurisprudencia/790210/recurso-especial-resp-982923/inteiro-teor12800095?ref=juris-tabs [Acesso em 10.nov.2017]

2 - Brasil. Decreto no 24.643, de 10 de julho de 1934. Decreta o Código de Águas. Disponível em: http://www.planalto.gov.br/ccivil 03/decreto/d24643.htm [Acesso em 10.nov.2017] 
3- Brasil. Lei no 10.406, de janeiro de 2002. Institui o Código Civil. Disponível em: http://www.planalto.gov.br/ccivil 03/leis/2002/l10406.htm [Acesso em 10.out.2017]

4. Freitas VP de. Sistema jurídico brasileiro de controle da poluição das águas subterrâneas. Revista de Direito Ambiental. 2001; 6(23):53-66.

5 - $\quad$ Brasil. Lei no 7.347, de 24 de julho de 1985. Disciplina a ação civil pública de responsabilidade por danos causados ao meio-ambiente, ao consumidor, a bens e direitos de valor artístico, estético, histórico, turístico e paisagístico (VETADO) e dá outras providências. Disponível em: http://www.planalto.gov.br/ccivil 03/leis//7347orig.htm [Acesso em 10.out.2017]

6 - Ministério do Meio Ambiente. Resolução CONAMA n 357, de 17 de março de 2005. Dispõe sobre a classificação dos corpos de água e diretrizes ambientais para o seu enquadramento, bem como estabelece as condições e padrões de lançamento de efluentes, e dá outras providências. Disponível em: http://www.mma.gov.br/port/conama/legiabre.cfm?codlegi=459 [Acesso em 15.out.2017]

7. Freitas VP de; Freitas GP de. Crimes contra a natureza. São Paulo: Editora RT, 2012.

8. Gerent J, Gonçalves A. Acordo sobre o Aquífero Guarani: proposta de um regime jurídico regional, Revista de Direito Ambiental. 2016; 83(21):209-225.

9 - Brasil. Constituição Federal de 1988. Disponível em:

http://www.planalto.gov.br/ccivil 03/constituicao/constituicaocompilado.htm [Acesso em 15.out.2017]

10. Steigleder AM. Responsabilidade civil ambiental: as dimensões do dano ambiental no direito brasileiro. Porto Alegre: Livraria do Advogado, 2017.

11 - Brasil. Lei no 9.433/1997, de 8 de janeiro de 1997. Institui a Política Nacional de Recursos Hídricos, cria o Sistema Nacional de Gerenciamento de Recursos Hídricos, regulamenta o inciso XIX do art. 21 da Constituição Federal, e altera o art. $1^{\circ}$ da Lei no 8.001, de 13 de março de 1990, que modificou a Lei no 7.990, de 28 de dezembro de 1989. Disponível em: http://www.planalto.gov.br/ccivil 03/leis/l9433.htm [Acesso em 15.out.2017]

12 - Brasil. Lei no. 9.984, de 17 de junho de 2000. Dispõe sobre a criação da Agência Nacional de Águas - ANA, entidade federal de implementação da Política Nacional de Recursos Hídricos e de coordenação do Sistema Nacional de Gerenciamento de Recursos Hídricos, e dá outras providências. Disponível em:

http://www.planalto.gov.br/ccivil 03/leis/L9984.htm [Acesso em 15.set.2017]

13 - Brasil. Lei Complementar no 140, de 8 de dezembro de 2011. Fixa normas, nos termos dos incisos III, VI e VII do caput e do parágrafo único do art. 23 da Constituição Federal, para a cooperação entre a União, os Estados, o Distrito Federal e os Municípios nas ações administrativas decorrentes do exercício da competência comum relativas à proteção das paisagens naturais notáveis, à proteção do meio ambiente, ao combate à 
poluição em qualquer de suas formas e à preservação das florestas, da fauna e da flora; e altera a Lei no 6.938, de 31 de agosto de 1981. Disponível em:

http://www.planalto.gov.br/ccivil 03/Leis/LCP/Lcp140.htm [Acesso em 15.set.2017]

14 - Ministério do Meio Ambiente. Resolução CONAMA nํ 370, de 6 de abril de 2006. Prorroga o prazo para complementação das condições e padrões de lançamento de efl uentes, previsto no art. 44 da Resolução no 357, de 17 de março de 2005. Disponível em: http://www.mma.gov.br/port/conama/legiabre.cfm?codlegi=496 [Acesso em 15.out.2017]

15 - Ministério do Meio Ambiente. Resolução CONAMA n 393, de 8 de agosto de 2007. Dispõe sobre o descarte contínuo de água de processo ou de produção em plataformas marítimas de petróleo e gás natural, e dá outras providências. Disponível em:

http://www.mma.gov.br/port/conama/legiabre.cfm?codlegi=541 [Acesso em 15.out.2017]

16 - Ministério do Meio Ambiente. Resolução CONAMA nํ 397, de 3 de abril de 2008. Altera o inciso II do $\S 40$ e a Tabela X do § 5, ambos do art. 34 da Resolução do Conselho Nacional do Meio Ambiente- CONAMA no 357, de 2005, que dispõe sobre a classificação dos corpos de água e diretrizes ambientais para o seu enquadramento, bem como estabelece as condições e padrões de lançamento de efluentes. Disponível em: http://www.mma.gov.br/port/conama/legiabre.cfm?codlegi=563 [Acesso em 16.out.2017]

17 - Brasil. Lei no 6.938, de 31 de agosto de 1981. Dispõe sobre a Política Nacional do Meio Ambiente, seus fins e mecanismos de formulação e aplicação, e dá outras providências. Disponível em: http://www.planalto.gov.br/ccivil 03/leis/l6938.htm [Acesso em 17.out.2017]

18 - Nunes R. Comentários ao Código de Defesa do Consumidor. São Paulo: Saraiva, 2015.

19 - Machado PAL. Direito Ambiental Brasileiro. São Paulo: Malheiros Editores, 2015.

20 - Brasil. Lei no 12.305, de 2 de agosto de 2010. Institui a Política Nacional de Resíduos Sólidos; altera a Lei no 9.605, de 12 de fevereiro de 1998; e dá outras providências. http://www.mma.gov.br/port/conama/legiabre.cfm?codlegi=636 Disponível em: [Acesso em 15.out.2017]

21 - Brasil. Decreto Federal no 7.404, de 24 de dezembro de 2010.

Regulamenta a Lei no 12.305, de 2 de agosto de 2010, que institui a Política Nacional de Resíduos Sólidos, cria o Comitê Interministerial da Política Nacional de Resíduos Sólidos e o Comitê Orientador para a Implantação dos Sistemas de Logística Reversa, e dá outras providências. Disponível em: www.mma.gov.br/port/conama/legiabre.cfm?codlegi=636 [Acesso em 20.out.2017]

22 - Antunes PB. Direito ambiental. São Paulo: Atlas, 2016.

23 - Brasil. Lei no 9.605, de 12 fevereiro de 1988. Dispõe sobre as sanções penais e administrativas derivadas de condutas e atividades lesivas ao meio ambiente, e dá outras 
providências. Disponível em: http://www.planalto.gov.br/ccivil 03/leis/19605.htm [Acesso em 20.out.2017]

24 - Brasil. Decreto no 6.514, de 22 de julho de 2008. Dispõe sobre as infrações e sanções administrativas ao meio ambiente, estabelece o processo administrativo federal para apuração destas infrações, e dá outras providências. Disponível em: http://www.planalto.gov.br/ccivil 03/ ato2007-2010/2008/decreto/d6514.htm [Acesso em 20.out.2017]

25 - Brasil. Lei no 12.305, de 2 de agosto de 2010. Institui a Política Nacional de Resíduos Sólidos; altera a Lei no 9.605, de 12 de fevereiro de 1998; e dá outras providências. Disponível em: http://www.planalto.gov.br/ccivil 03/ ato20072010/2010/lei//12305.htm [Acesso em 20.out.2017]

Como citar este artigo:

Bettim DA, Costa RF. Análise da decisão do Recurso Especial no 982.923-PR: aspectos essenciais do direito fundamental à saúde e ao meio ambiente equilibrado em caso de contaminação de lençol freático. Revista Cadernos Ibero-Americanos de Direito Sanitário. 2018 jan./mar, 7(1):318-328. 